may result in a greater spread of $\mathrm{TB}$ among their contacts. However, new studies are needed to determine risk factors at the individual level, in order to guide preventive actions for silicosis and $\mathrm{TB}$ in regions with silica exposure activities.

\section{RELATIONSHIP BETWEEN SPIROMETRIC VALUES AND THE HISTORY OF ENVIRONMENTAL EXPOSURE TO ASBESTOS IN A COMMUNITY IN THE STATE OF MEXICO}

\begin{abstract}
${ }^{1,2}$ Genezareth Miranda-Figueroa*, ${ }^{1,2}$ Gladys Martínez-Santiago, ${ }^{3}$ Guadalupe AguilarMadrid. ${ }^{1}$ Programa Único de Especialidades Medicas, Universidad Nacional Autónoma de México; ${ }^{2}$ Hospital Central Sur de Alta Especialidad, Petróleos Mexicanos; ${ }^{3}$ Unidad de Investigación de Salud en el Trabajo, Instituto Mexicano del Seguro Social
\end{abstract}

\subsection{6/oemed-2018-ICOHabstracts.1275}

Introduction It has been established that environmental exposure due to residence in the vicinity of factories where asbestos use is associated with the risk of lung disorders.

Objective To relate the history of environmental exposure to asbestos, with spirometric values of an adult population of the community of San Pedro Barrientos, Tlalnepantla in the state of Mexico.

Material and methods A spirometry accompanied by a questionnaire of occupational and environmental exposure to a sample of 123 adult inhabitants, who had a history of having lived in the community for at least a year in the period was performed, and respiratory symptoms ranging from 19431998, during which time he was one of the active processing plants nation's largest asbestos.

Results The equations that best adjusted to calculate the predicted values in the study population, forced expiratory volume in one second (FEV1) and forced vital capacity (FVC) were the NHANESIII study of Mexico-American population (June, 2001).

A negative correlation between years of residence in the community found Barrientos, with the percentage obtained in the FEV1/FVC, FVC and FEV1 with a value of $-0.05,-0.16$ and -0.22 respectively. Which is an indicator of the tendency to have lower percentages in spirometric values increased residence time in the community.

Conclusions Given that spirometry is the most accessible to evaluate mechanical ventilation test, and is useful for the diagnosis and monitoring of various diseases, efforts should be made to make it available and perform as recommended standardisation in order to have acceptable and reproducible manoeuvres. It is important to note the trend of the results, which indicate that the longer the exposure subjects had lower percentages predicted spirometry values (adjusted for sex, age and height).

The result of this research supports the recommendations issued by the United Nations (UN) and the International Labour Organisation (ILO), which states that there is no safe level of exposure to asbestos and should promote the elimination of Use in whatever form and materials containing.

We recommend further studies extension to the population and evaluated the study spirometry to identify any histopathological damage by environmental exposure to asbestos, as well as make the surrounding population studies that community spirometry.
1375 ASSOCIATION BETWEEN AGE-STRATIFIED OBSTRUCTIVE SLEEP APNEA SYNDROME AND OBESITY

${ }^{1} \mathrm{~S}$ Nogami*, ${ }^{2} \mathrm{H}$ Seki, ${ }^{3} \mathrm{~K}$ Maruyama, ${ }^{4} \mathrm{~T}$ Tanigawa, ${ }^{1} \mathrm{~N}$ Suganuma. ${ }^{1}$ Department of Environmental Medicine, Kochi Medical School, Kochi University, Nankoku, Japan; ${ }^{2}$ Department of otorhinolaryngology, Niyodo Hospital, Ino, Japan; ${ }^{3}$ Laboratory of Community Health and Nutrition, Special Course of Food and Health Science, Department of Bioscience, Graduate School of Agriculture, Ehime University, Matsuyama, Japan: ${ }^{4}$ Department of Public Health, Graduate School of Medicine, Juntendo University, Tokyo, Japan

\subsection{6/oemed-2018-ICOHabstracts.1276}

Introduction Obstructive sleep apnea (OSA) among publictransportation drivers becomes a social concern in a certain number of traffic accidents. Major risk factors of OSA were reportedly obesity and ageing; however, age stratified relationship between OSA and risk factors have yet to be evaluated. This study aimed to evaluate the association between OSA and obesity stratified by age-groups.

Methods One hundred and fifty-five bus drivers were screened by the flow sensor method, to detect subject with a respiratory disturbance index (RDI) more than 15. Then, portable polysomnography (PSG) tests were performed to measure an apnea hypopnea Index (AHI): subjects with $\mathrm{AHI} \geq 40$ were diagnosed as OSA; for those with $20 \leq \mathrm{AHI}<40$ full PSG tests were performed. Portable PSG AHI $\geq 20$ was diagnosed as OSA. Relationship between OSA and BMI were statistically compared in three age-groups; younger than 40,40 to 49 , and 50 and older by the logistic regression analysis and unpaired t-test.

Result Of the 152 subjects $(45.2 \pm 9.3$ year-old, BMI 24.5 \pm 4.5 ) after excluding 4 subjects (unexamined by PSG), 55 subjects showed RDI $>15$ by the screening test and underwent PSG. 25 subjects were diagnosed as a definite OSA. BMI was significantly associated with OSA with OR of 1.17 (95\% CI: 1.06 to 1.29). ORs for OSA become greater as the age increased showing greatest $\mathrm{OR}$ in 50 and older (OR 5.15, 95\% CI: 1.17 to 22.8). Mean BMI of OSA subjects with younger than 40 was greater than that of non-OSA (BMI 34.8 \pm 9.3 and $23.1 \pm 5.2$, respectively, $\mathrm{p}=0.0012)$, however, no difference was found in those with $40-49$ and 50 and older.

Discussion The result suggests weight reduction may more effective for younger drivers. Obesity of the drivers is highly associated with OSA for younger than 40, while ageing is more correlated with OSA than obesity for 50 and older.

\section{RESPIRATORY SYMPTOMS IN COFFEE WORKERS OF LAVRAS - MINAS GERAIS}

${ }^{1}$ DMM Lima, ${ }^{2}$ SH Penido, ${ }^{1}$ CB Ferreira, ${ }^{1}$ DNPDella Torre*, ${ }^{1} J R$ Rezende, ${ }^{3}$ ALH Penido, ${ }^{1}$ APS Carneiro. ${ }^{1}$ Hospital das Clínicas da Universidade Federal de Minas Gerais, Belo Horizonte-MG, Brasil; ${ }^{2}$ Faculdade de Ciências Médicas de Minas Gerais, Belo Horizonte MG, Brasil, ${ }^{3}$ Faculdade de Medicina de Marilia, Marilia - SP, Brasil

\subsection{6/oemed-2018-ICOHabstracts. 1277}

Introduction The importance of coffee to the country can be verified by the Brazilian leadership in world production and export, as well as being the second largest consumer of the product in the world (MINISTRY OF AGRICULTURE, 2017). The literature shows that coffee processing workers are subject to a higher 